\title{
MID SHAFT CLAVICULAR FRACTURE- A RETROSPECTIVE, RANDOMISED STUDY OF COMPARISON OF OUTCOMES BETWEEN TENS NAILING AND CONSERVATIVE TREATMENT
}

Amit Sehgal, Paras Gupta, Amit Kumar, Chavi Sethi, Ajai Vikram Singh, Deepak Shrivastava, Rupesh Kumar

1. Consultant Orthopedician. Department of Orthopaedics, MLB Medical College. Jhansi.

2. Associate Professor. Department of Orthopaedics, MLB Medical College. Jhansi.

3. Junior Resident. Department of Orthopaedics, MLB Medical College. Jhansi.

4. Lecturer. Department of Anesthesia, MLB Medical College. Jhansi.

5. Lecturer. Department of Anesthesia, MLB Medical College. Jhansi.

6. Junior Resident. Department of Anesthesia, MLB Medical College. Jhansi.

7. Assistant Professor. Department of Anesthesia, MLB Medical College. Jhansi.

\section{CORRESPONDING AUTHOR:}

Dr .Amit Sehgal,

J /41 Ajay enclave, Galla Mandi road,

Jhansi p.c. - 284002.

E-mail: dr_chavi @yahoo.com

INTRODUCTION: The clavicle is an oblong bone that connects the shoulder girdle to the trunk. It provides support and mobility for upper extremity function.

- Anatomically, the acromioclavicular and coracoclavicular ligament attach the clavicle to the scapula laterally.

- The sternoclavicular and the costoclavicular ligaments anchor the clavicle medially. The sternocleidomastoid and the subclavius muscles also have points of attachment to the clavicle.

- The clavicle also protects the adjacent brachial plexus, lung, and blood vessels.

\section{GROUP 1:}

- Approximately $80 \%$ of clavicle fractures occur in the middle third.

- Most class A fractures occur medial to the coracoclavicular ligament, at the junction of the middle and outer thirds of the clavicle.

The proximal fragment is typically displaced upward because of the pull of the sternocleidomastoid muscle. The usual mechanism of injury involves a direct force.

GROUP 2: $15 \%$ involve the distal or lateral third. Group 2 fracture result from a direct blow to the top of the shoulder.

They occur distal to the coracoclavicular ligament and are classified further into 3 subtypes.

- Type I fractures are nondisplaced, and the coracoclavicular ligaments remain intact.

- Type II fractures are displaced, and there is associated rupture of the coracoclavicular ligament with the proximal clavicular segment typically pulled upward by the sternocleidomastoid muscle.

- Type III injuries involve the articular surface of the acromioclavicular joint.

\section{GROUP 3:}


- Less than 5\% involve the proximal or medial third.

- Fractures of the medial third occur as a result of a direct blow to the anterior chest.

\section{OBJECTIVE}

- To analyze the functional outcome of conservative Vs intramedullary fixation of fracture mid shaft clavicle

- To analyse the time of union after conservative Vs intramedullary fixation of fracture mid shaft clavicle

- To analyse the complication rate after conservative Vs intramedullary fixation of fracture mid shaft clavicle.

MANAGEMENT: There is a lot of controversy for the management of fracture midshaft clavicle in choosing b/w operative or conservative method. In the past most fracture midshaft clavicle were treated by conservative method but with the introduction of modern technique, trends changed from conservative to operative treatment to reduce the incidence of non union, shortening \& limited function

MATERIALS AND METHODS: This study will be conducted on patients with fracture of midshaft clavicle, admitted in the Emergency and O.P.D. of orthopedics Department of M.L.B. Medical College and Hospital, Jhansi (U.P.)

\section{PATIENTS SELECTION}

\section{INCLUSION CRITERIA}

- Displacement $>2 \mathrm{~cm}$

- Shortening $>2 \mathrm{~cm}$

- Increasing communication (> 3 fragments)

- Segmental fractures

- Upto Gustilo Anderson type-II injuries

- Obvious clinical deformity (usually associated with items 1 and 2 )

- Compliant pt of 16-60 yr age who have active recreational lifestyle

- Bilateral clavicle fracture

- Mid shaft clavicular fracture associated with other injury

\section{EXCLUSION CRITERIA}

- Fracture more than 15 days old

- Impending open fracture with soft tissue compromise (Gustilo Anderson type III injury)

- Scapular malposition and winging on initial examination

- Multiple injuries

- Patient not willing to cope with any two (conservative vs intramedullary nailing) modalities of treatment

- Vascular injury requiring repair

- Progressive neurologic deficit

- Ipsilateral upper extremity injuries / fractures

- Multiple Ipsilateral upper rib fracture

- Floating shoulder

- Poly trauma with requirement for early upper extremity weight bearing / arm use 
MATERIAL: A. INSTRUMENTS

- BP handle with surgical blade

- Double hook retractor

- Bone holding clamp

- Image Intensifier

- Orthopaedic traction table.

- Suction machine

B. IMPLANTS: Titanium elastic nails.

- $1.5 \mathrm{~mm}$

- $2 \mathrm{~mm}$

- $2.5 \mathrm{~mm}$

\section{PROFORMA}

- Name : Reg. No.

- Age and sex D.O.A. :

- Address :

- Occupation: M.O.I.C.

- Duration of Injury :

- Associated Injury/Fracture

- Any Significant past / family history

- Any treatment taken prior to admission

- Physical; examination (positive findings only).

- Systemic

- Local including

- Distal intravascular status

\section{INVESTIGATION}

1. Haemogram

2. Blood Urea

3. Blood glucose fasting and P.P.

4. EKG

5. Chest X-ray PA View

X-RAY : Apical lordotic views (an AP view with the tube directed $45^{\circ}$ cephalic) may be required to define the degree of displacement.

3D C.T. Scan, MRI if and when required.

OBSERVATION: These observation are based on the 50 patients with fracture midshaft clavicle that were admitted at M.L.B Medical College Jhansi, between the period of Jan 2010 to oct 2012 .

After clinicoradiological diagnosis the patients were treated conservatively as well as surgically by intramedullary TENS nail, under general anesthesia. The patients were followed up in the OPD after discharge at regular interval. The results were evaluated on the basis of constant score. The results were tabulated in Appendix. Observation were as follows- 
AGE DISTRIBUTION: The age group of the patients was 20-60 yrs in which most of the patients were between $20-40$ yes

Table-1: Showing age distribution

\begin{tabular}{|c|c|c|}
\hline Sex & No. of Patients & Percentage \\
\hline $20-30$ yrs & 16 & 32 \\
\hline 30-40yrs & 15 & 30 \\
\hline $40-50 y r s$ & 11 & 22 \\
\hline $50-60 y r s$ & 8 & 16 \\
\hline
\end{tabular}

SEX DISTRIBUTION: Out of 30 cases 22 (73.33\%) were males and 8 (26.67\%) were females. This shows male preponderance

Table-2: Showing sex distribution

\begin{tabular}{|c|c|c|}
\hline Sex & No. of Patients & Percentage \\
\hline MALE & 37 & 74 \\
\hline FEMALE & 13 & 26 \\
\hline TOTAL & 50 & 100 \\
\hline
\end{tabular}

\section{MODE OF INJURY}

The most common cause for fracture clavicle injury is RTA.

Table-3: Distribution of patients according to mode of injury.

\begin{tabular}{|c|c|c|}
\hline Mode of injury & No. of patients & Percentage \\
\hline RTA & 34 & 68 \\
\hline Sport injury & 3 & 6 \\
\hline Fall on out stretched arm on ground & 13 & 26 \\
\hline
\end{tabular}

TIME SINCE INJURY

Table-4: Distribution of patients according to time since injury.

\section{SIDEDNESS-}

\begin{tabular}{|c|c|c|}
\hline TIME & CONSERVATIVE & SURGICAL \\
\hline 0-12 hr & 7 & 9 \\
\hline 12-24hr & 5 & 8 \\
\hline 1-3day & 6 & 7 \\
\hline 3-7day & 3 & 2 \\
\hline 7-14day & 5 & 2 \\
\hline >14day & 4 & 2 \\
\hline
\end{tabular}


In our study most of the patient are Rt side clavicle fracture

Table-5: Distribution of patients according to sidedness

\begin{tabular}{|c|c|c|}
\hline Sidedness & Patient & Percentage \\
\hline Right & 35 & 70 \\
\hline Left & 15 & 30 \\
\hline
\end{tabular}

ASSOCIATED INJURY: In our study most of the clavicle fracture (50\%) are associated with other fracture in the body like femur, tibia, pelvis etc.

Table-6: Distribution of cases according to associated injury.

\begin{tabular}{|c|c|c|}
\hline Associated injury & No. Of patients & Percentage \\
\hline Not associated & 20 & 40 \\
\hline Associated with Head injury & 8 & 16 \\
\hline Associated with other fracture & 22 & 44 \\
\hline
\end{tabular}

FRACTURE PATTERN: Out of 50 fractures, commonly 20 were longitudinal, 12 were oblique, 5 were wedge and 8 were segmental

Table-7: Distribution of patients according to fracture pattern

\begin{tabular}{|c|c|l|}
\hline Fracture pattern & No. of patients & Percentage \\
\hline Simple\longitudinal & 20 & 40 \\
\hline Oblique & 12 & 40 \\
\hline Wedge & 5 & 10 \\
\hline Segmental & 8 & 16 \\
\hline
\end{tabular}

TYPE OF WOUND: Most of the fractures were closed 50\%but open were graded according to Gustillo's grading system and $33.67 \%$ were grade I but $16.67 \%$ were of grade-II. Grade III fractures were not included in the study.

Table-8: Showing distribution of open or closed fractures

\begin{tabular}{|l|c|c|}
\hline Gustillo's grade & No. of patients & Percentage \\
\hline CLOSED & 38 & 76 \\
\hline GRADE I & 8 & 16 \\
\hline GRADE II & 4 & 8 \\
\hline
\end{tabular}

TYPE OF MANAGEMENT: In our study total 30 patients are included among which 15 are managed by conservative method and 15 were managed by surgical (TENS).

Table- 9: Distribution of cases according to type of management. 


\begin{tabular}{|c|c|c|}
\hline Type of management & No. of patients & $\mathbf{\%}$ \\
\hline Conservative & 25 & 50 \\
\hline Surgical (TENS) & 25 & 50 \\
\hline
\end{tabular}

UNION ACHIEVED: Union assessed radiologically. On an average union was achieved in 8 - 12 weeks

Table-10: Distribution of cases according to time of union.

\begin{tabular}{|c|c|c|}
\hline Time of union & Conservative & Surgical \\
\hline 4-6 weeks & 4 & 6 \\
\hline 6-8weeks & 8 & 15 \\
\hline 8-10weeks & 8 & 7 \\
\hline 10-12weeks & 10 & 2 \\
\hline
\end{tabular}

TIME OF REMOVAL OF IMPLANT:- Implant is removed when union is achieved radiologically and clinically i.e. at three months.

\section{POST OP COMPLICATION}

Table-11: Distribution of cases according to post-op complication.

\begin{tabular}{|l|c|c|c|c|}
\hline \multicolumn{1}{|c|}{ Complication } & Conservative & $\mathbf{\%}$ & Surgical & $\mathbf{\%}$ \\
\hline Cosmetic problem & 20 & 66.67 & 10 & 100 \\
\hline Stiffness & 20 & 33.34 & 5 & 26.67 \\
\hline Pin tract infection & 0 & 0 & 1 & 6.67 \\
\hline Skin irritation & 0 & 0 & 4 & 6.67 \\
\hline Non union & 6 & 20 & 1 & 6.67 \\
\hline Mal union & 25 & 100 & 0 & 0 \\
\hline Reverse medial perforation & 0 & $0 \%$ & 2 & 6.67 \\
\hline Neurovascular damage & 0 & $0 \%$ & 0 & 0 \\
\hline Shortening & 25 & 100 & 0 & 0 \\
\hline
\end{tabular}

FUNCTIONAL EVALUATION; Functional outcome for fracture clavicle is evaluated by trained physiotherapist according to constant score.

Table-12 : Distribution of cases according to constant score.

\begin{tabular}{|c|c|c|c|c|c|}
\hline \multirow{2}{*}{ S.No. } & Type of management & No. of patients & \multicolumn{3}{|c|}{ Constant score (range) } \\
\cline { 4 - 6 } & & & 1 week & 6 week & 12 week \\
\hline \multirow{2}{*}{1} & Surgical & 16 & $80-84$ & $94-96$ & $94-96$ \\
\cline { 4 - 6 } & Conservative & 14 & $80-84$ & $92-94$ & $92-94$ \\
\hline
\end{tabular}




\begin{tabular}{|c|c|c|c|c|c|}
\hline 2 & Surgical & 10 & $80-82$ & $92-94$ & $92-94$ \\
\cline { 2 - 6 } & Conservative & 12 & $80-84$ & $90-92$ & $90-92$ \\
\hline \multirow{2}{*}{3} & Surgical & 4 & $80-82$ & $90-92$ & $92-94$ \\
\cline { 2 - 6 } & Conservative & 4 & $78-80$ & $88-90$ & $90-92$ \\
\hline
\end{tabular}

DURATION OF IMMOBILIZATION: For conservatively managed PATIENT it is 3 week and for surgically managed patient it is 1 week in arm sling pouch

DURATION OF HOSPITAL STAY: For operative patient it is1-3 day

DISCUSSION: Simple closed fracture of the mid third clavicle is a frequent injury mostly treated nonoperatively. Although fracture healing and functional outcome is unusually satisfactory (3), significant shortening with mal-union or non-union is described in the literature $(7,21,22)$. Whereas some authors reports good function result in patients with clavicular shortening, Matis et al., found an impaired should function in half of their patients with clavicular shortening function in half of their patients with a shortening of $1 \mathrm{~cm}$ and in $100 \%$ when shortening was 2 $\mathrm{cm}$. Hill et al., reported a clear correlation of non-unions (15\%) with clavicular shortening of more than $2 \mathrm{~cm}$. they found unsatisfactory results in $31 \%$ of completely displaced midclavicular fracture after nonoperative treatment. Besides non-union residual persistent pain, brachial plexus irritation and poor cosmetic results were observed. According to Jupiter and Leffert, the initial displacement is one of the most predisposing factors in the development of non-unions. Furthermore nonoperatively treated clavicular fractures cause pain, discomfort, and disability which are often not adequately appreciated by the treating physician.

For patients with a high demand on should function, such prospects are barely acceptable. To meet these patients expectations a minimally invasive procedure which provides restoration of the clavicular length combined with early resumption of training, completely functional recovery and a good cosmetic result may be an attractive alternative to nonoperative management.

Open reduction with plate fixation is the operative standard treatment for clavicular shaft fractures. Potential complication include deep infection, injury to the subclavian vessels, screw lessening with implant failure, non-union and refracture after hardware removal. Bostman et al., reported a complication rate of $23 \%$ following plate fixation. The cosmetic result is frequently considered unsatisfactory caused by an inevitable and often hypertrophic scar. Due to these problems nonoperative treatment of midclavicular fracture is still favored by most surgeons.

In contrast TENS as a potential alterative overcomes several disadvantages of plate fixation. The incision is kept short, providing a better cosmetic result. Restoration of clavicular length can reliably be maintained with minimal exposure and a limited amount of hardware. In about half of the interventions closed reduction of the fracture is successful, which provides the best conditions for undisturbed fracture healing. Even when open reduction can not be avoided, exposure can be kept to a minimum in order to avoid additional tissue damage. Most patients can be treated as day cases and full mobility of the shoulder is achieved early on. As postoperative instructions for the patients include no restriction regarding range of motion the level of activity is determined only by pain and the patient's motivation for an early resumption of full shoulder function. Despite this rather aggressive postoperative regimen we observed 
neither implant failure nor migration. This failure was clearly the result of the surgeon's misjudgment and could not be attributed to the operation technique itself. All other fractures healed correctly resulting in a symmetrical shoulder girdle.

Resumption of training with full function was achieved by all patients within $\backslash 8-12$ weeks postoperatively.

Intramedullary fixation of clavicular shaft fractures is not a new ideas; it dates back to Lambotte at the beginning of the last century. Murray (14) published his technique of intramedually Kirschner wire fixation in 1940. Since then, numerous technical variations have been published $(9,10,15,20)$. Implant migration with fatal complication, implant failure and maland non-union have been described in the literature $(4,19)$. Due to the complication rate which exceeds the problems of non-operative management, all these techniques have never found general acceptance.

In contrast to Kirschner wire fixation, TENS is a truly intramedually stabilization technique. The flexile Titanium nail is firmly anchored in the S-shaped clavicle according to the principles described by Ligier et al., (11). The largest series of TENS for midclavicular fractures so far was published by Jubel et al., (6) in 2002. In their case series 65 midclavicular fractures were stabilized applying TENS technique. Patients age ranged from 13 to 74 years. Unlike our study, they also included patients with neurovascular involvement, multiple injuries and floating shoulders. No major complications were observed.

Intramedullary advancement of the blunt Titanium nail makes an injury to the neurovascular structure very unlikely. No such complication has been described in the literature using this technique. Other fatal complications like implant migration into the chest cavity have not been observed either. Migration in a lateral direction would cause damage to the acromioclavicular joint whereas migration medially would simply lead to skin perforation. We observed 1 case of skin perforation, but this complication was caused by a direct blow to the medial end of the Titanium nail which lies directly underneath the skin, and it was not related to implant migration.

Despite our enthusiasm for TENS in midclavicular fracture, we remain restrictive regarding its indications. In our opinion nonoperative management is still the gold standard which provides good results in most cases, leaving TENS as a valuable technique for selected cases. From a technical point of view simple fractures with a lack of bony contact or with considerable shortening are ideal indications. For fractures with one intermediary is crucial. Can be safely performed if the two main fragments have osseous contact after reduction, ensuring correct clavicular length with the Titanium nail in place. If the intermediary fragment involves the entire clavicular circumference it is mandatory to string this fragment as well in order to prevent secondary shortening and implant perforation through the skin. TENS can certainly not be recommended for comminuted fracture as the above principles do not apply in these fracture patterns.

Further studies are necessary comparing TENS with nonoperatively treatment. The cost needs to be justified against the potential patient risk and statistically significant improvements need to be demonstrated for different patients groups.

In selected case TENS is a safe and effective method for midclavicular fracture with a low complication rate once potential technical pitfalls are appreciated. Restoration of clavicular length is reliable. Cosmetic and functional results are excellent and a quick recovery makes early resumption of training possible. 
The functional score we use is based on the constant score, which is based on the function of shoulder. So for better assessment there is a need to develop a functional outcome score validated for fracture clavicle treatment.

CONCLUSION: This study was conducted at Dep't of Orthopaedic M.L.B Medical College Jhansi comprise of 50 patients admitted to this hospital from Jan 2010 to Oct 2012. Patients were treated conservatively as well as intramedullary fixation by TENS nailing.

- This study shows that operative treatment with TENS nailing has better functional outcome than conservative treatment in mid shaft displaced clavicular fracture.

- The timing of union is less in operative cases than conservative..

- The overall complication rate is higher in conservative treatment

- The result of conservative treatment is almost similar to TENS nailing if shortening of clavicle is $<2 \mathbf{c m}$.

- In future for better assessment, there is need to develop a functional outcome score validated for clavicle fracture treatment.

- Overall observation that intramedullary fixation by TENS nailing is alternative option for fixation of midshaft clavicular fracture and better for fixation in athletes.

- This technique provides more rapid free movement of the shoulder and an earlier return to daily activities than the conservative treatment.

\section{BIBLIOGRAPHY:}

1. Batsman O, Massinen M, Pihlajamaki H. Complications of plate fixation in fresh displaced miclavicular fracture. J. Trauma. 1997; 43: 778-783.

2. Constant CR. A cliical; method of cuntional assessment of the should. Clin. Orthop. 1987; 214; 60-164.

3. Eskola A, Vainonpaa S. Myllynen P. et al., Outcome of clavicular fracture in 89 patients. Arch Orthop Trauma Surg. 1986; 105: 337-338.

4. Glauser F, Kremens V. Unusual sequela following pinning of medial clavicles fracture. Am. J. Roentgennol Radium Ther Nucl Med. 1956; 76: 1066-1069.

5. Hill JM, McGuire MH, Crosby LA. Closed treatment of displaced middle-third fracture of the clavicle gives poor result. J Bone Joint Surg. 1997; 79-B: 537-539.

6. Jubel A, Andermahr J, Schiffer G. Rehm KE. The technique of elastic-stable intrameduallary nailing of midclavicualr fracture. Unfallchirurg. 2002; 105: 511-516.

7. Jupiter J.B., Leffert RD. Non-union of the clavicle. J. Bone Jopint Surg 1987; 69-A: 753760.

8. Klonz A, Hockertz T, Rellmann H, Klavikulafrakturen. Unfallchirug. 2001; 104: 70-81.

9. Lengua F, Nuss JM, Lechner R et al., Treatment of fractures of the clabicle by closed pinning inside-out without back and forther. Rev. Chir. Orthop. 1987; 73: 377-380.

10. Leppilahti J, Jalovaara P. Migration of Kirschner wires following fixation of the clavicle: A report of 2 cases. Acta Orthop Scand. 1999; 70: 517-519.

11. Ligier JN, Metazeau JP, Prevot J. Closed flexible intramedullary nailing in paediatric traumatology. Chir Pediatr. 1983; 24: 283-285.

12. Matis N, Kwasny 0, Gaebier C. Effects of clavicular shortening after clavicualr fracture. Hefte Unfallchirug. 1999; 275; 314-315.

13. Mekee MD, Wild LM, Schemitsch EH, Midshaft malunions of the clavicle. J Bone Surg. 2003; 85-A: 790-797. 
14. Murray G, QA method of fixation for fracture of the clavicle. J. Bone Joint Surg. 1940; 22: 616-620.

15. Ngarmukos C, Parkpian V. Patradul A. Fixation of fractures of the midshaft of the clavicle with Kirschner wires. Result in 108 patients. J. Bone Joint Surg. 1998; 80-B: 106-108.

16. Nordqvist A, Redlund-Johnell I, von Scheele A, Petersson CJ. Shortening of clavicle after fracture. Indience and clinical significance, a 5-year follow-up of 85 patients. Acta Orthop Scand. 1997; 68: 349-351.

17. Robinson CM. Fractures of the clavicle in the adult. J. Bone Joint Surg. 1998; 80-B: 476484.

18. Rowe CR. An atlas of anatomy and treatment of midclavicular fracture. Clin Orthop. 1968; 58: 29-42.

19. Schwarz N, Sim E, Pienaar S. The treatment of shaft fractures of the clavicle. Eur J. Traua. 2001: 27: 211-217.

20. Wllkins RM, Johnston RM, Ununited fractures of the clavicle. J Bone Surg. 1983; 65-A: 773-778.

21. Zlowodzki M, Zelle BA, Cole PA, et al; Treatment of acute midshaft clavicle fractures: systematic review of 2144 fractures: on behalf of the Evidence-Based Orthopaedic Trauma Working Group. J Orthop Trauma. 2005 Aug;19(7):504-7. [abstract]

22. Quillen DM, Wuchner M, Hatch RL; Acute shoulder injuries. Am Fam Physician. 2004 Nov 15;70(10):1947-54. [abstract]

23. Brilliant LC; Fractures, Clavicle. eMedicine. July, 2009.

24. Shoulder dystocia, Royal College of Obstetricians and Gynaecologists (2005).

25. Allman FL Jr; Fractures and ligamentous injuries of the clavicle and its articulation. J Bone Joint Surg Am. 1967 Jun;49(4):774-84.

26. Clavicle Fractures, Wheeless' Textbook of Orthopaedics.

27. Nowak J, Holgersson M, Larsson S; Sequelae from clavicular fractures are common: a prospective study of 222 patients. Acta Orthop. 2005 Aug;76(4):496-502. [abstract]

28. No authors listeds. J Bone Joint Surg Am. 2006 Jan;88(1):35-40. ; Nonoperative treatment compared with plate fixation of displaced midshaft clavicular fractures. A multicenter, randomized clinical trial. J Bone Joint Surg Am. 2007 Jan;89(1):1-10.

29. McKee MD, Pedersen EM, Jones C, et al; Deficits following nonoperative treatment of displaced midshaft clavicular fracture

30. RobinsJubel A, Andermahr J, Prokop A, et al; Treatment of mid-clavicular fractures in adults. Early results after rucksack bandage or elastic stable intramedullary nailing. Unfallchirurg. 2005 Sep;108(9):707-14.

31. Qureshi F, Hinschea A, Pottera D; Arthroscopic 'tightrope' stabilisation of neer type 2 clavicular fractures. Science Direct. January 2007.

32. on CM, Court-Brown CM, McQueen MM, et al; Estimating the risk of nonunion following nonoperative treatment of a clavicular fracture. J Bone Joint Surg Am. 2004 Jul;86A(7):1359-65.

33. Robinson CM, Cairns DA; Primary nonoperative treatment of displaced lateral fractures of the clavicle. J Bone Joint Surg Am. 2004 Apr;86-A(4):778-82.

34. Amir Estephan, "Fracture, Clavicle", http://emedicine. medscape. com/ article/824564overview assessed on 3 April 2010, 5.40 am.

35. 14) Djahangiri A \& Farron A, "When to operate an isolated midshaft clavicle fracture?", Rev Med Suisse] 2009 Aug 5; Vol. 5 (212), pp. 1542-5, Medline. 
36. ) Jeevan Chandrasenan, Sachin Badhe, Timothy Cresswell \& Joe De Beer, "The Clavicular Hook Plate: Consequences in Three Cases", Eur J Trauma Emerg Surg 2007, No. 5, URBAN \& VOGEL, 2007.

37. Kevin J Eerkes, "Clavicular Injuries", http://emedicine. medscape. com/ article/92429overview assessed on 3 April 2010, 5.20 am.

38. Liu PC, Chien SH, Chen JC et al, "Minimally invasive fixation of displaced midclavicular fractures with titanium elastic nails.", J Orthop Trauma 2010 Apr; Vol. 24 (4), pp. 21723, Medline.

39. L Joseph Rubino, "Clavicle Fractures", http://emedicine. medscape.com/article/1260953-overview assessed on 3 April 2010, $5.30 \mathrm{am}$.

40. Oguz Cebesoy, "Percutaneous fixation in fractures of the distal third of the clavicle: simpler, cheaper, better", International Orthopaedics, 31:129, Springer-Verlag, 2006.

41. Prinz KS, Rapp M, Kraus R et al, "Dislocated midclavicular fractures in children and adolescents: who benefits from operative treatment?", Z Orthop Unfall 2010 Jan, Vol. 148 (1), Medline.

42. Shin SJ, Roh KJ, Kim JO \& Sohn HS, "Treatment of unstable distal clavicle fractures using two suture anchors and suture tension bands.", Injury, Dec; Vol. 40 (12), pp. 1308-12, Medline, 2009.

43. S. P. Badhe, T. M. Lawrence, \& D. I. Clark, "Tension band suturing for the treatment of displaced type 2 lateral end clavicle fractures", Arch Orthop Trauma Surg, 127:25-28, Springer-Verlag, 2006.

44. Vinzenz Smekal, Juergen Oberladstaetter, Peter Struve \& Dietmar Krappinger, "Shaft fractures of the clavicle: current concepts", Arch Orthop Trauma Surg (2009) 129:807815, Springer-Verlag, 2008.

45. Yih-Shiunn Lee, Ming-Jye Lau \& Ya-Chun Tseng, "Comparison of the efficacy of hook plate versus tension band wire in the treatment of unstable fractures of the distal clavicle", International Orthopaedics, 33:1401-1405, Springer-Verlag, 2008.

46. Minimally Invasive Intramedullary Nailing of Midshaft Clavicular Fractures Using Titanium Elastic Nails by Mueller, Marcus MD; Rangger, Christoph MD, PhD; Striepens, Nadine MD; Burger, Christof MD, Journal of Trauma-Injury Infection \& Critical Care: June 2008 - Volume 64 - Issue 6 - pp 1528-1534 


\section{AO/OTA CLASSIFICATION FOR FRACTURE CLAVICLE}

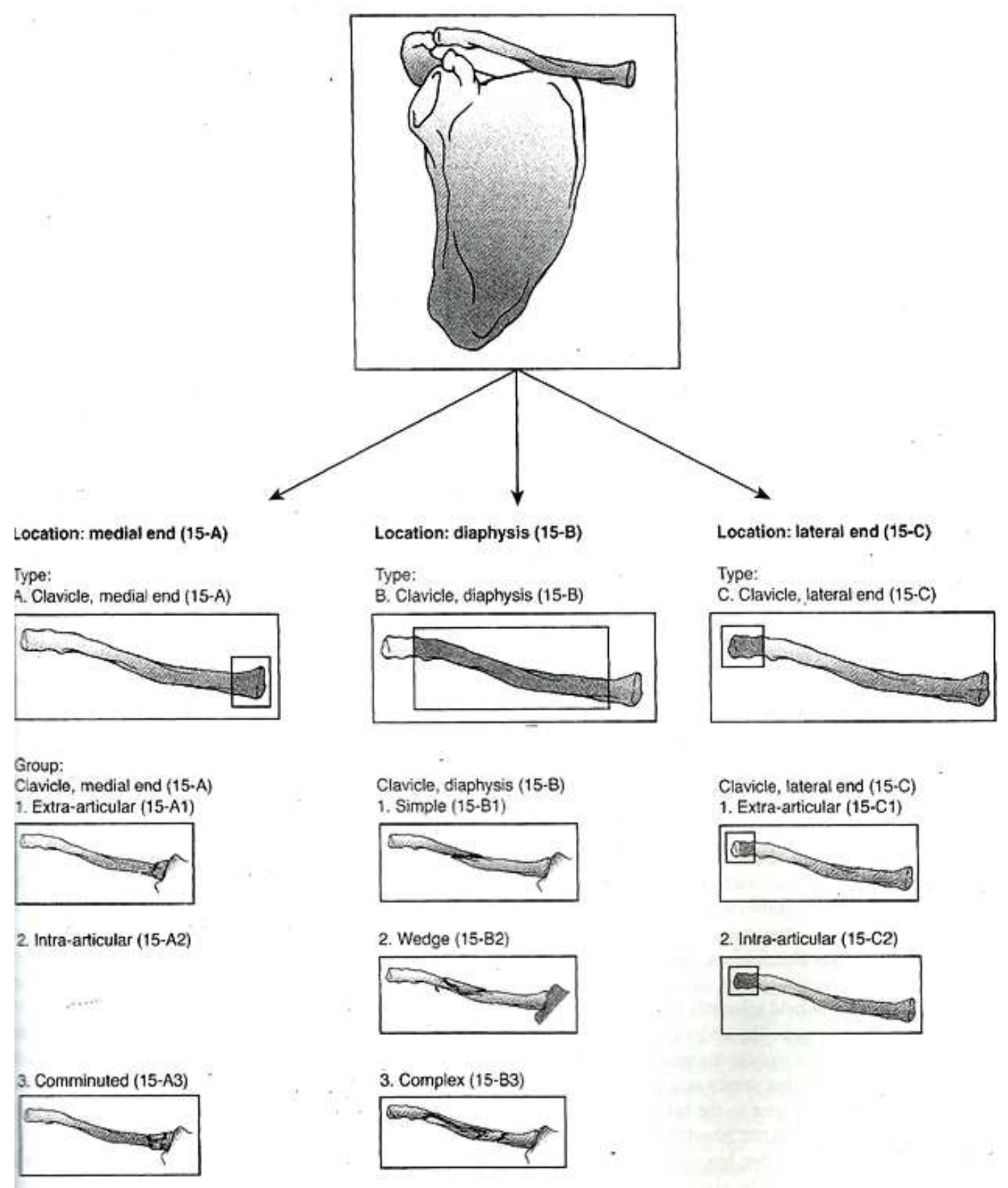




\section{ORIGINAL ARTICLE}

\section{DESIGN OF STUDY}

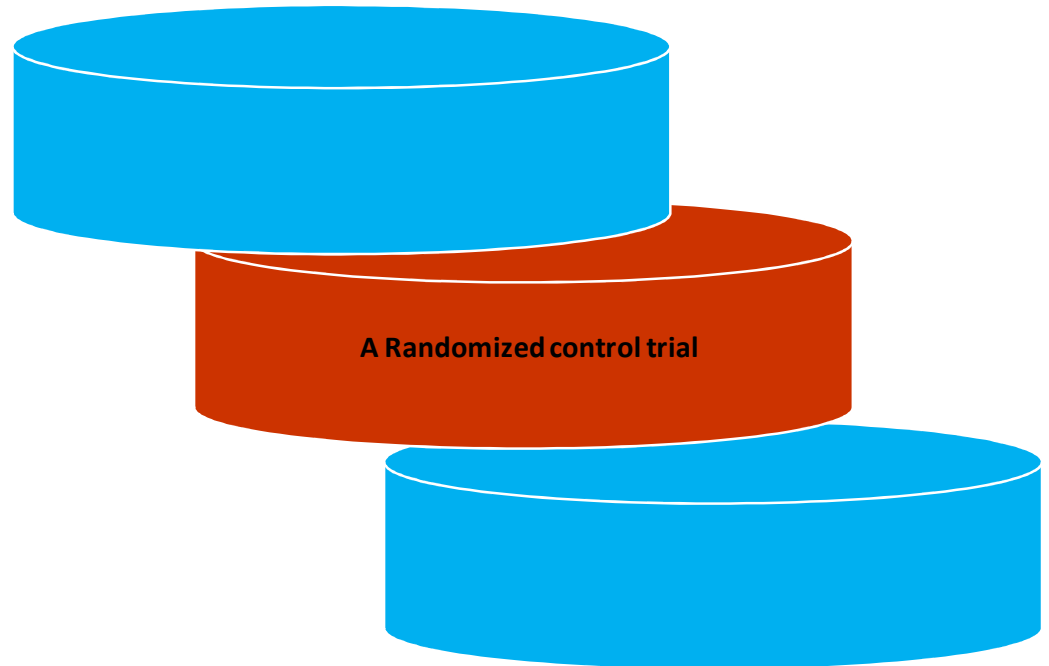

MANAGEMENT
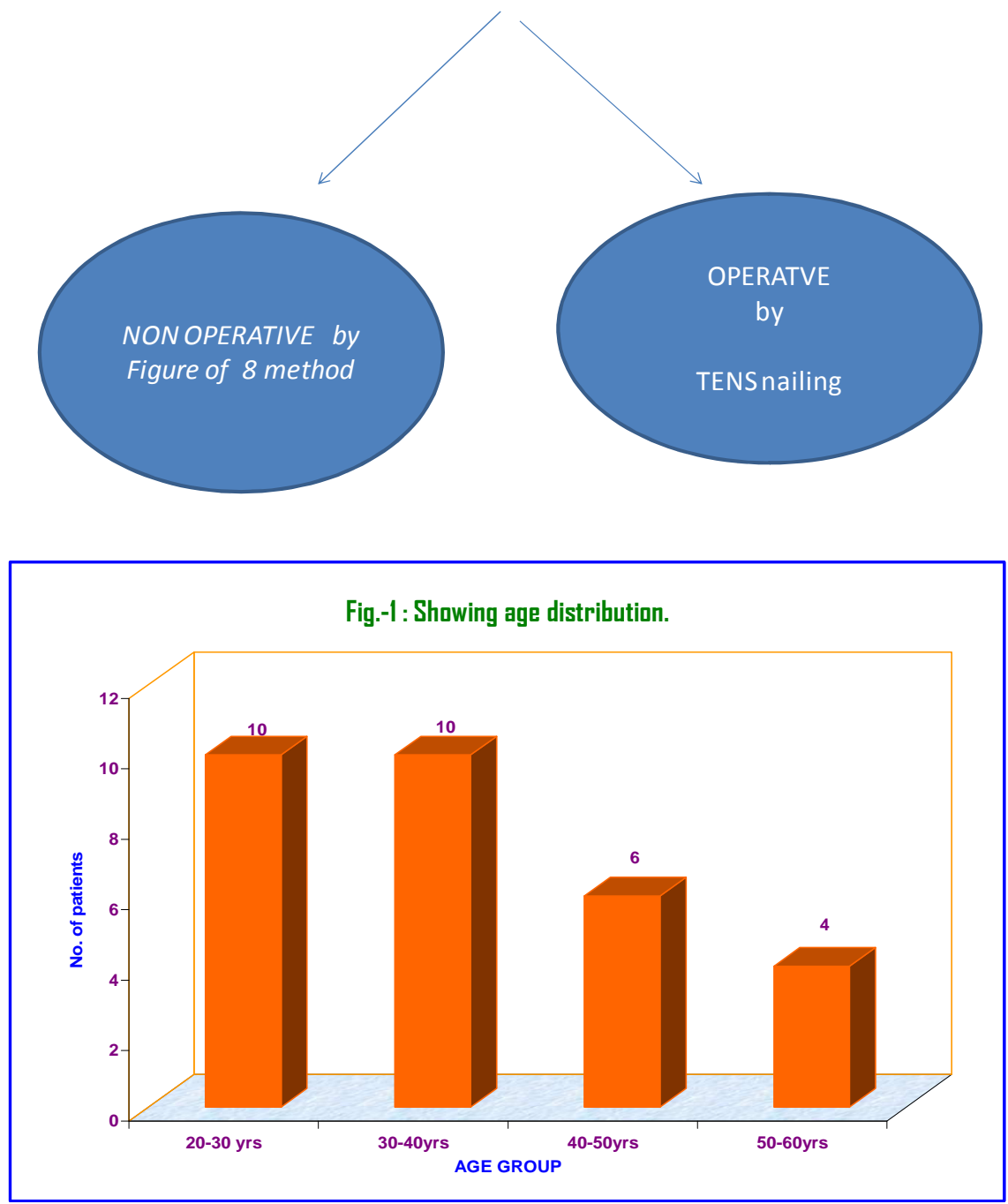

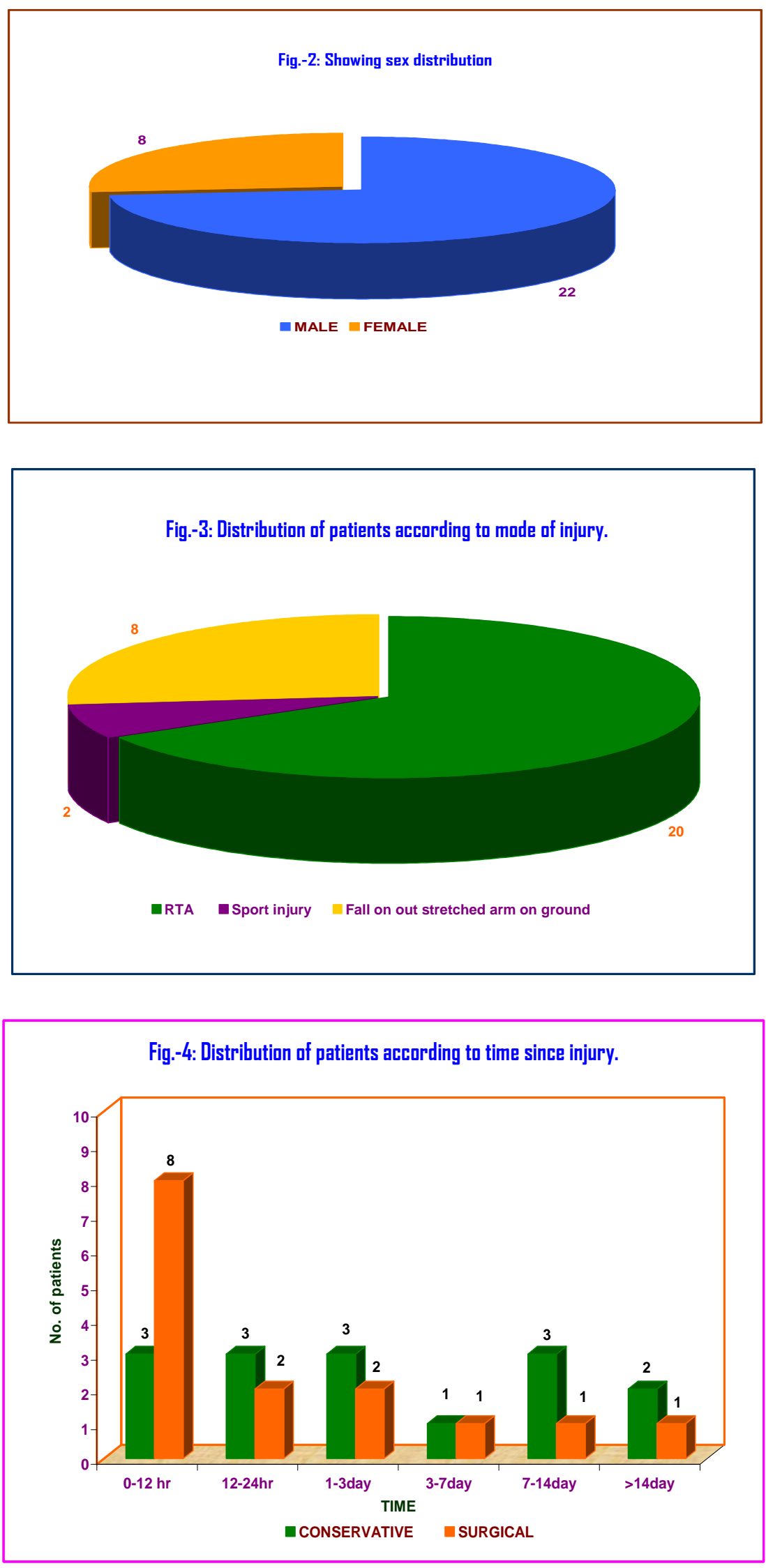


\section{ORIGINAL ARTICLE}
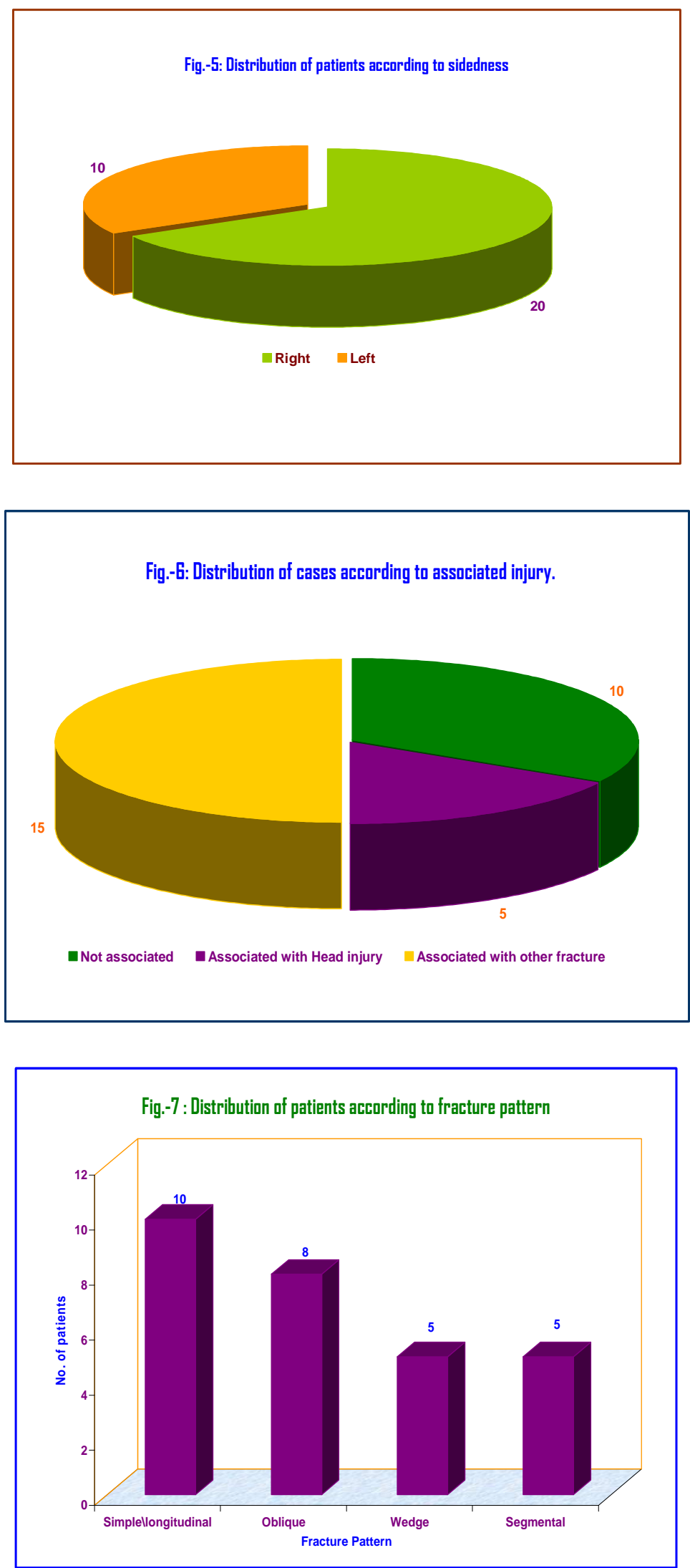


\section{ORIGINAL ARTICLE}
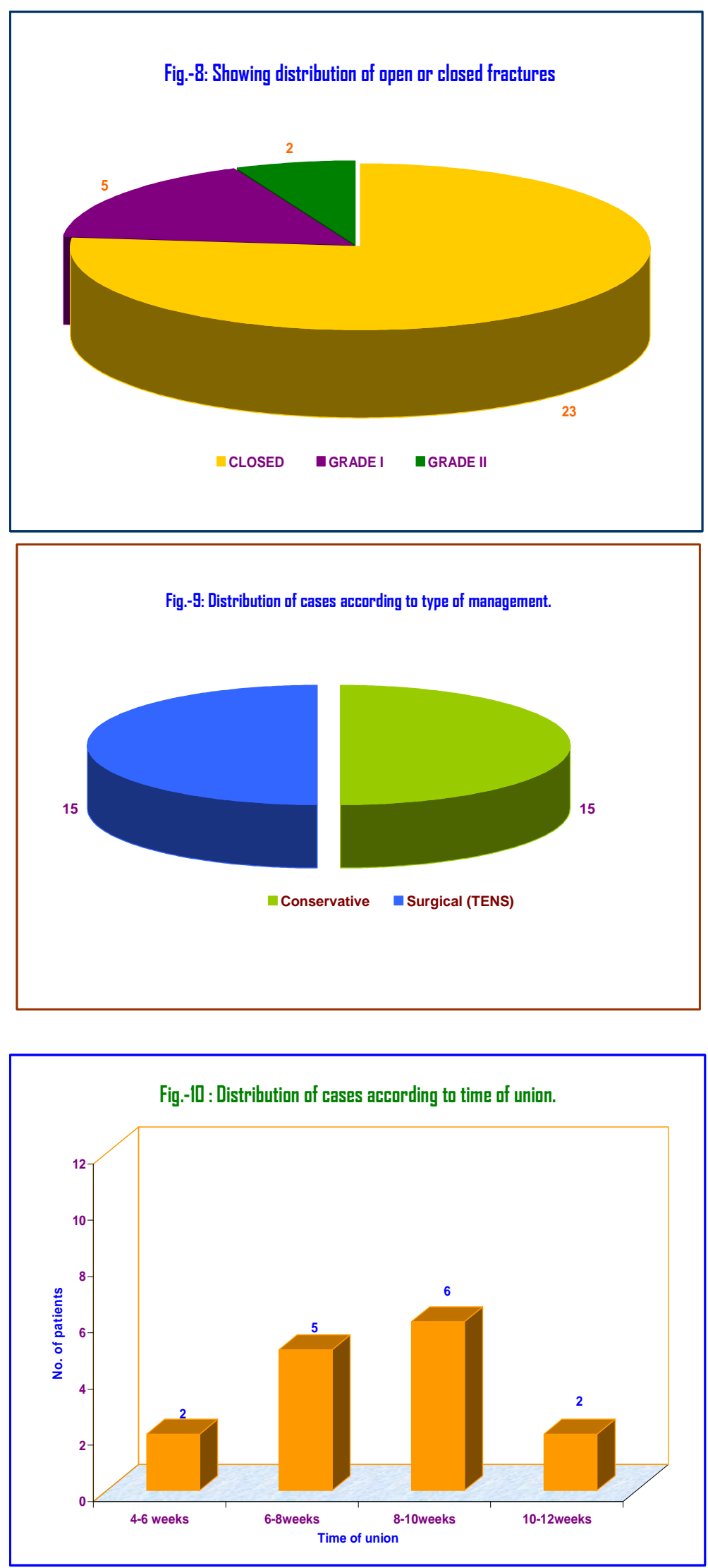


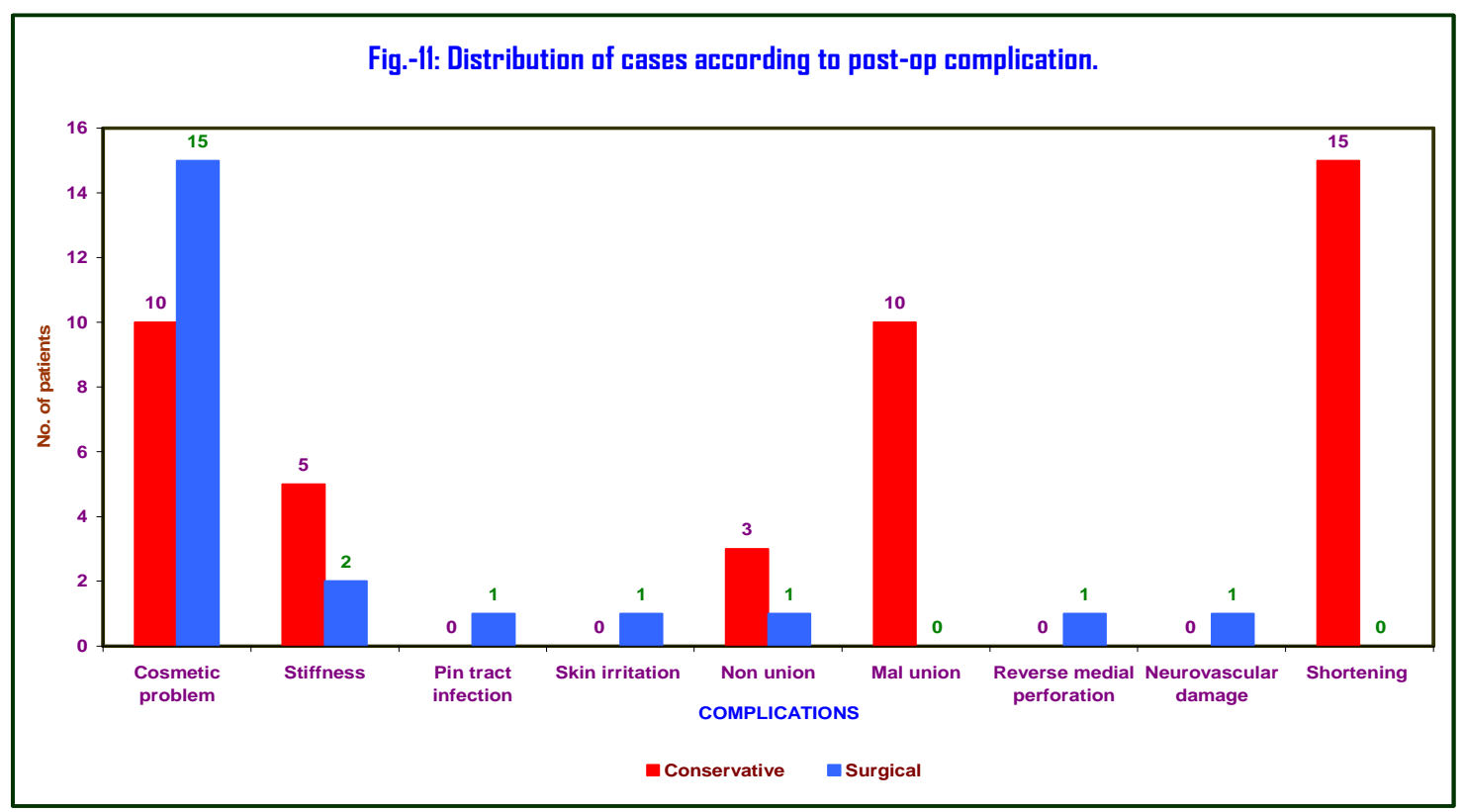

